\title{
Specific aspects of hybrid bearings working at high rotational speeds: the influence of the recess pressure pattern
}

\author{
Mathieu Hélène, Mihai ArghiR and Jean Frêne \\ Laboratoire de Mécanique des Solides, UMR CNRS 6610, SP2MI, Bd Marie et Pierre Curie, BP 30179, \\ 86962 Futuroscope Chasseneuil Cedex, France
}

Received 28 March 2003, accepted 6 February 2004

\begin{abstract}
Hydrostatic bearings working at high rotational speeds are usually designed as hybrid bearings. They benefit of a load carrying capacity at low or zero speed and of a reduced torque at high working regimes. Therefore they are provided with pockets or recesses fed via hydraulic restrictors. Modeling the flow in these pockets and its coupling with thin film in the bearing is not a straightforward task. Comparisons with experimental data have shown that the capacity of correctly predicting the bearing characteristics (mainly the dynamic coefficients) is influenced by the accurate modeling of the pressure pattern in the pockets. The present work presents typical recess pressure patterns and shows the way they can influence on the bearing characteristics.
\end{abstract}

Key words: Lubrication / hybrid bearings / Navier-Stokes / pressure pattern / dynamic characteristics

Résumé - Modélisation spécifique des paliers hybrides fonctionnant à des vitesses de rotation très élevées : l'influence du profil de pression dans l'alvéole. Les paliers hydrostatiques opérant à très hautes vitesses de rotation sont communément dénommés paliers hybrides (régime mixte hydrostatique/hydrodynamique). Ces paliers possèdent l'avantage de garantir une capacité de charge à vitesse nulle et bénéficient d'un couple de frottement fortement réduit dans des conditions de fonctionnement sévères. La contribution hydrostatique s'effectue par des alvéoles placées dans le coussinet et alimentées par l'intermédiaire de résistances hydrauliques (comme des capillaires ou des orifices). Une modélisation prenant en compte la nature complexe de l'écoulement dans une telle alvéole ainsi que le couplage avec la partie film mince du palier n'est pas une tâche simple. De plus, des comparaisons avec des données expérimentales ont prouvé que seule une analyse fine de la répartition de la pression dans une alvéole pouvait garantir l'obtention de résultats réalistes, notamment en termes de coefficients dynamiques. Ce travail présente des profils de pression typiques de paliers hybrides ainsi que la manière dont ils peuvent influencer les caractéristiques globales du palier.

Mots clés : Lubrification / paliers hybrides / Navier-Stokes / profil de pression / caractéristiques dynamiques

\section{Introduction}

Hybrid Journal Bearings (HJB) present a growing interest in industry in particular for supporting devices in very high-speed turbomachinery applications. This type of bearing should bring several advantages compared to the traditional ball bearings, in particular with regard to the reduction of friction and wear in concert with better dynamic behavior, which is a guarantee of the best life span. A hybrid bearing is composed of $n$ identical

\footnotetext{
a Corresponding author:

mihai.arghir@lms.univ-poitiers.fr
}

recesses (or pockets) regularly disposed on the circumference of the bush. Figure 1 presents an example of a complete hybrid bearing with 4 rectangular recesses, fed with a supply pressure $P_{\mathrm{s}}$.

HJB usually work at high rotation speeds and are fed at important supply pressures. The theoretical modeling of HJB has then two aspects, namely the correct description of the flow field in the thin film lands and the description of the recess pressure field.

Concerning the flow in the thin film lands, the combined effects of the journal rotation and of the important supply pressure lead to very high Reynolds numbers. The reduced Reynolds number $R e^{*}=R e \cdot H / L$ (where $H$ 


\section{Nomenclature}

\begin{tabular}{|c|c|}
\hline$C$ & centered radial clearance $[\mathrm{m}]$ \\
\hline$C_{X X}, C_{X Y}, C_{Y X}, C_{Y Y}$ & damping coefficients $\left[\mathrm{Ns} \cdot \mathrm{m}^{-1}\right]$ \\
\hline$C_{\mathrm{D}}$ & orifice discharge coefficient \\
\hline$d_{\text {orifice }}$ & orifice diameter $[\mathrm{m}]$ \\
\hline$e_{X}, e_{Y}$ & eccentricity $[\mathrm{m}]$ \\
\hline$f_{\mathrm{R}}, f_{\mathrm{S}}$ & rotor and stator friction factors \\
\hline$F_{X 1}, F_{Y 1}$ & perturbation fluid film forces in $X$ and $Y$ directions [N] \\
\hline$H$ & film thickness $[\mathrm{m}]$ \\
\hline$K_{X X}, K_{X Y}, K_{Y X}, K_{Y Y}$ & stiffness coefficients $\left[\mathrm{N} \cdot \mathrm{m}^{-1}\right]$ \\
\hline$L$ & bearing length $[\mathrm{m}]$ \\
\hline$M_{X X}, M_{X Y}, M_{Y X}, M_{Y Y}$ & inertia or added mass coefficients $[\mathrm{kg}]$ \\
\hline$P_{\mathrm{s}}, P_{\mathrm{r}}, P_{\mathrm{e}}$ & supply, recess and edge pressures $\left[\mathrm{N} \cdot \mathrm{m}^{-2}\right]$ \\
\hline$R$ & shaft radius $[\mathrm{m}]$ \\
\hline$R e$ & Reynolds number \\
\hline$t$ & time $[\mathrm{s}]$ \\
\hline$U, W$ & fluid mean flow velocities in circumferential and axial directions $\left[\mathrm{m} \cdot \mathrm{s}^{-1}\right]$ \\
\hline$V_{\mathrm{n}}$ & recess edge normal velocity \\
\hline$z$ & axial direction \\
\hline$\theta$ & circumferential direction \\
\hline$\vartheta$ & recess volume $\left[\mathrm{m}^{3}\right]$ \\
\hline$\xi$ & empirical entrance loss coefficient \\
\hline$\Omega$ & rotational speed of journal $\left[\mathrm{rad} \cdot \mathrm{s}^{-1}\right]$ \\
\hline$\omega$ & perturbation (whirl) frequency $\left[\mathrm{rad} \cdot \mathrm{s}^{-1}\right]$ \\
\hline$\rho$ & density $\left[\mathrm{kg} \cdot \mathrm{m}^{-3}\right]$ \\
\hline$\mu$ & dynamic viscosity $[\mathrm{Pa} \cdot \mathrm{s}]$ \\
\hline$\tau$ & shear stress $[\mathrm{Pa}]$ \\
\hline \multicolumn{2}{|l|}{ Subscripts: } \\
\hline $\mathrm{R}, \mathrm{S}$ & rotor (shaft), stator \\
\hline
\end{tabular}

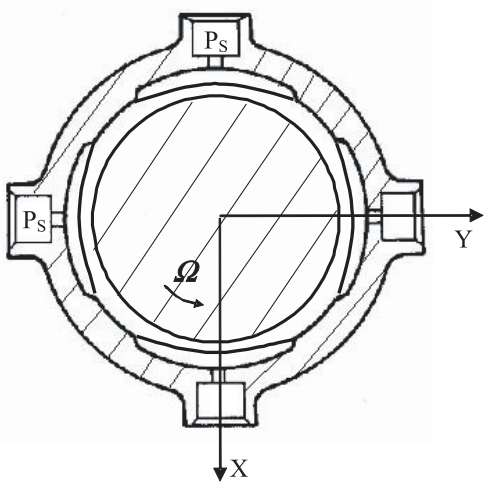

Fig. 1. Hybrid journal bearing.

and $L$ are the characteristic length scales of the film thickness and of the film length, respectively) becomes then greater than unity, showing that inertia forces have a dominant effect in the transport equations. The classical lubrication models based on the Reynolds equation that exclude inertia effects are then inapplicable.
The appropriate model is the so called "bulk-flow" system of equations that consists of a continuity equation and of two momentum equations for the coupled pressure and velocity fields $[1,2]$. Its solution techniques are different from those used for the Reynolds equation [1].

The second peculiar aspect of HJB modeling is the recess pressure field. Several studies showed that under certain conditions (very high Reynolds numbers and shallow pockets) the pressure in the recess of the hybrid bearing is not constant. A peculiar attention will be given to this problem which represents the central point of the present work and the next paragraph is a literature review dedicated to this topic.

\subsection{The non-constant pressure in a shallow recess and the necessity of a pressure pattern}

First, Chaomleffel and Nicolas [3] presented in 1985 the results of measurements in a recess of a hybrid bearing showing a non-constant pressure in the downstream part of the pocket. Next, in 1991, 
San Andrès and Velthuis [4] performed a complete twodimensional Navier-Stokes analysis of the steady laminar flow of an incompressible fluid in a recess. They showed that the pressure in the recess zone is not uniform, contrary to what was supposed in the traditional lubrication theory. Indeed, the pressure decreases upstream and increases downstream because of the hydrodynamic effect related to the shaft rotation.

Braun and Dzodzo [5] studied in 1994 the influence of the pocket depth and of the operating conditions of a hydrostatic bearing on the flow and on the pressure pattern by numerical integration of the two-dimensional NavierStokes equations. The fluid was incompressible and the flow was laminar, corresponding to low Reynolds number operating regimes. The authors were interested in the nature and in the position of the recirculation zones within the recess and in their influence on the circumferential flow rate. They noticed that for deep pockets, the coupling between the pressure pattern and the operating conditions was much less noticeable than for shallow pockets. Inertia effects at the edge of the recess were also investigated.

In 1996, Braun et al. [6] presented full threedimensional Navier-Stokes calculations to model the laminar flow of an incompressible fluid in a deep pocket of a hydrostatic bearing. The work primarily concerned the recirculation zones and their effects on the circumferential and axial flow rates. The inertia effects were studied for two different operating conditions: a jet dominated flow due to the hydrostatic contribution and a Couette dominated flow due to the shaft rotation. For the jet dominated flow, the pressure within the pocket was almost constant excepted at the recess edges where an abrupt pressure drop occurs due to the "Rayleigh step" effect. For the Couette dominated flow, the authors noticed that the pressure reached a higher level than for the jet dominated one, but was still constant. Lastly, Braun and Dzodzo $[7,8]$ presented a three-dimensional modeling of the laminar and incompressible flow in shallow pockets admitting several height/width aspect ratios and also simulated the eccentricity effect of the rotor. In this case, contrary to a deep pocket, they showed that the recess pressure distribution couldn't be regarded as constant any more but increases in the direction of rotation of the rotor.

It can be concluded from the above that pressure in shallow recesses of a HJB is not constant and the main variations occur in the circumferential direction. The pressure variation in the symmetry plane of the bearing is usually designed as "the pressure pattern" and is depicted in Figure 1. It can be seen that the pressure pattern can be first affected by the inflow of the hydraulic restrictor which impacts on the rotor; this phenomenon is so-called "jet effect". Next, the "hydrodynamic effect" is generated by the shaft rotation that creates a large pressure rise in the circumferential direction, from the upstream to the downstream end of the recess. Finally, due to strong concentrated interactions between inertia and viscous forces, pressure drops occurs at circumferential and axial edges of the recess. These pressure variations are predominant in shallow recesses of HJB to be used in industrial applications involving compressible fluids and operating at high rotational speeds (cryogenic turbopumps) were the volume of the fluid entrapped in the recess must be reduced in order to avoid "pneumatic hammer" instabilities. Since the Reynolds equation and the bulk-flow model cannot handle these types of pressure variations, a complete Navier-Stokes analysis should be carried out in the recess area. It is not yet possible to systematically perform such of an analysis for an entire HJB because of the very large computational effort. The only feasible approach is to make a three-dimensional NavierStokes analysis of an isolated recess and then to link the obtained results to the thin film land description via appropriate boundary conditions.

\section{The theoretical model}

\subsection{The bulk-flow system of equations}

The system of bulk-flow equations for incompressible and isothermal flow can be written under the form of three convective transport equations.

$$
\begin{gathered}
\frac{\partial H}{\partial t}+\frac{\partial(H W)}{\partial z}+\frac{\partial(H U)}{R \partial \theta}=0 \\
\rho\left[\frac{\partial H W}{\partial t}+\frac{\partial\left(H W^{2}\right)}{\partial z}+\frac{\partial(H W U)}{R \partial \theta}\right]= \\
-H \frac{\partial P}{\partial z}+\tau_{\mathrm{S} z}+\tau_{\mathrm{R} z} \\
\rho\left[\frac{\partial H U}{\partial t}+\frac{\partial(H U W)}{\partial z}+\frac{\partial\left(H U^{2}\right)}{R \partial \theta}\right]= \\
-H \frac{\partial P}{R \partial \theta}+\tau_{\mathrm{S} \theta}+\tau_{\mathrm{R} \theta}
\end{gathered}
$$

The viscous part lumped in the right hand side of the above equations is expressed under the form proposed by Hirs [9].

$$
\begin{aligned}
& \tau_{\mathrm{S} z}=\tau_{\mathrm{S}} \frac{W}{V_{\mathrm{S}}}, \quad \tau_{\mathrm{S} \theta}=\tau_{\mathrm{S}} \frac{U}{V_{\mathrm{S}}}, \quad \tau_{\mathrm{S}}=\frac{1}{2} \rho f_{\mathrm{S}} V_{\mathrm{S}}^{2} \\
& \tau_{\mathrm{R} z}=\tau_{\mathrm{R}} \frac{W}{V_{\mathrm{R}}}, \quad \tau_{\mathrm{R} \theta}=\tau_{\mathrm{R}} \frac{U-R \Omega}{V_{\mathrm{R}}}, \quad \tau_{\mathrm{R}}=\frac{1}{2} \rho f_{\mathrm{R}} V_{\mathrm{R}}^{2} \\
& V_{\mathrm{S}}=\sqrt{W^{2}+U^{2}}, \quad V_{\mathrm{R}}=\sqrt{W^{2}+(U-R \Omega)^{2}}
\end{aligned}
$$

The friction factors can be expressed by a Blasius'type law for the laminar and the turbulent flow regime:

$$
f=a R e^{b}, \quad R e=2 \rho V H / \mu,
$$

where $a=24, b=-1$ for laminar flow or $a=0.079$, $b=-0.25$ for turbulent flow. Several other laws can be employed for turbulent regime (Moody, Colebrooke, etc.). 


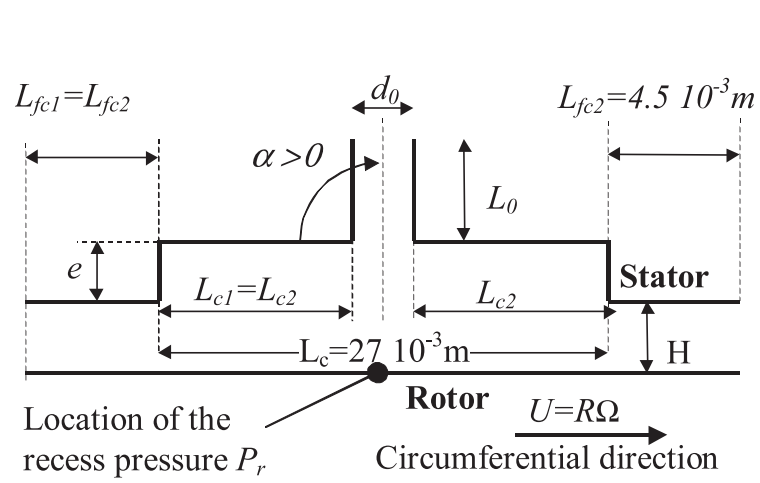

(a)

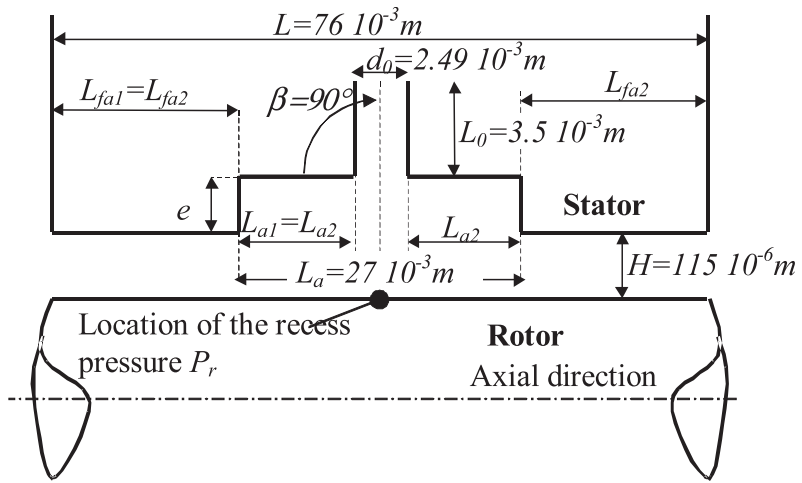

(b)

Fig. 2. (a) Circumferential cross section of the recess. (b) Axial cross section of the recess.

Boundary conditions are imposed in terms of pressures and tangential velocities; the normal component of the velocity on the boundary is part of the solution algorithm. The tangential velocity on the recess edge is considered to be zero, which means that the flow leaving the recess is directed perpendicular to its edge. Pressures must be imposed on the two axial exit sections of the bearing and on the edges of the recesses. The pressure on the two axial end sections is usually the ambient one. Pressures on the recess edges are part of the solution and are linked to the pocket flow. Their correct description is of capital importance for the accuracy of the model and is given by the pressure pattern.

\subsection{Analysis of the flow in an isolated recess of a HJB}

The flow in an isolated recess of a HJB is modeled using a complete three-dimensional Navier-Stokes analysis. Circumferential and axial cross sections of the recess depicting the geometric characteristics are displayed in Figures $2 \mathrm{a}, \mathrm{b}$. The rotor radius is $38 \mathrm{~mm}$. The thin film curvature is neglected compared to the other bearing dimensions and a constant film thickness is considered over the whole domain. This model physically corresponds to a centered position of the rotor. The problem can be described as the flow in a cavity where the fluid is supplied via an injector. Being also driven by the viscous force of the moving wall the flow can enter or leave the domain via the thin film area. Various types of pressure patterns can thus be obtained.

Results of three-dimensional Navier-Stokes analysis of the flow in a single recess are presented in this paragraph. Two operating conditions are simulated. In both cases the supply pressure is $5.5 \mathrm{MPa}$. The first case corresponds to pure hydrostatic operating conditions with no shaft rotation while the second case enlightens the hybrid regime (hydrostatic and hydrodynamic) generated by a shaft rotational speed of $24600 \mathrm{rpm}$.

Figures $3 \mathrm{a}, \mathrm{b}$ depict rotor pressure surface plots for the two operating regimes, whereas Figures $4 a$, b display profiles of the rotor pressure surface in the axial and in the circumferential directions. A jet effect is located in the restrictor area and is due to the high supply pressure. This abrupt pressure peak is quite important regarding to the overall pressure range but its influence is located closely around the restrictor area. For zero shaft velocity a non-constant pressure is to be expected between the jet impact region and the upstream and the downstream film lands (Figs. 4a and 3b). This decreasing pressure is the hydrostatic effect. If the shaft rotates (Figs. 3b and 4b), a hydrodynamic effect is superposed to the hydrostatic regime. This effect is characterized by a pressure rise from the upstream to the downstream side of the recess and, when added to the hydrostatic pressure pattern, abrupt pressure variations occur at the recess edges. For zero shaft velocity (which means pure hydrostatic regime) these pressure drops are similar on all edges (Figs. 4a and 3a, b). With increasing shaft velocity (i.e. when the hydrodynamic pressure generation inside the recess becomes important) the abrupt pressure variations at the recess edges are quite different in the axial direction and in the circumferential direction. While the axial pressure drops conserve the same characteristics, the upstream pressure drop becomes hardly noticeable and the downstream one is largely increased. The pressure level in the recess is also quite larger for the hybrid regime due to the hydrodynamic contribution (Figs. 4a, b). These features of the pressure pattern must be parametrically described and then linked to the thin film model. This is the goal of the next paragraph. The parametric description is enabled by the use of the Reynolds number based on the bearing working conditions. The link of the recess pressure variation with the bulk-flow model is made possible by employing the local land velocities at the interface between the pocket and the thin film.

\subsection{Pressure patterns}

\subsubsection{Pattern 1: constant pressure [10]}

The first conclusion extracted from Figure $4 \mathrm{a}$ is that, excepting the area influenced by the impinging jet, the recess pressure may be considered as being almost constant in the axial and the circumferential direction. 


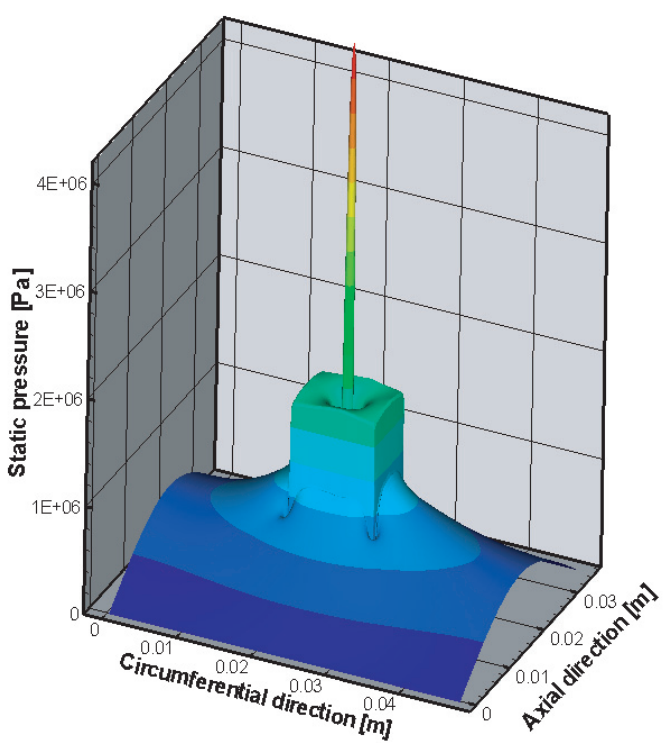

(a)

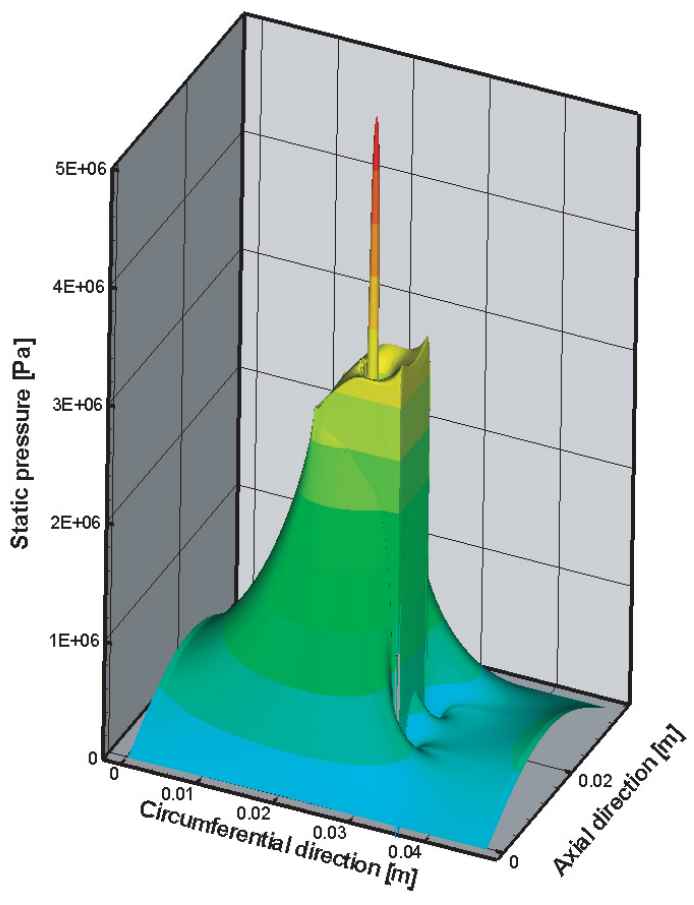

(b)

Fig. 3. Rotor pressure distribution: (a) zero rotational speed, (b) non-zero rotational speed.

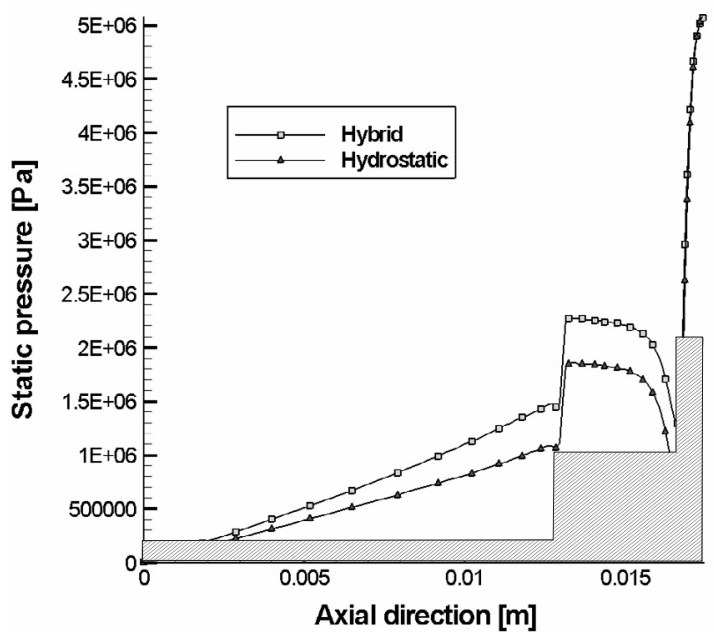

(a)

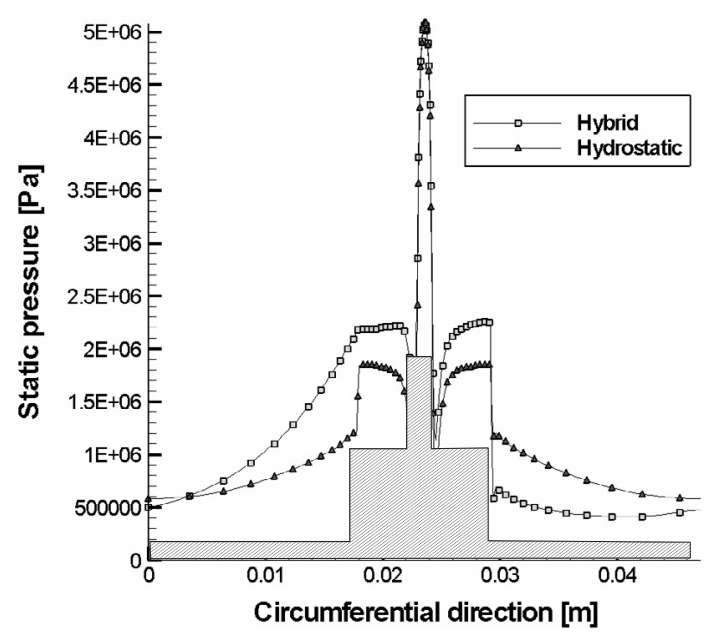

(b)

Fig. 4. Mid-plane rotor pressure variations: (a) in the axial direction, (b) in the circumferential direction.

This conclusion is also sustained by the surface plots depicted in Figures 3a, b. It then follows that the simplest pattern is to consider a constant recess pressure $P_{\mathrm{r}}$. The pressure peaks induced by the orifice jet impinging the rotor surface are then neglected. The edge pressure, $P_{\mathrm{e}}$, at the interface between the pocket and the thin film land are calculated by adding the pressure drop to the constant recess pressure $P_{\mathrm{r}}$.

$$
P_{\mathrm{e}}=P_{\mathrm{r}}-\Delta P_{\text {edge }}^{\text {recess }}
$$

$$
\begin{aligned}
& \Delta P_{\substack{\text { edge } \\
\text { edecs }}}=(1+\xi)\left(1-\eta^{2}\right)\left(1+1.95 R e_{H}^{-0.43}\right) \frac{\rho V_{n}^{2}}{2} \\
& \eta=\frac{H}{H+e}, \quad R e_{H}=\frac{\rho|\Omega R| H}{\mu}
\end{aligned}
$$

The pressure drop is expressed via the recess edge normal velocity, $V_{\mathrm{n}}$, thus ensuring the link between the thin film flow and the recess pressure. Moreover, this velocity is intimately related to the local thin film thickness $H$ and thus enables taking naturally into account eccentricity effects. For the axial direction, the correction term 


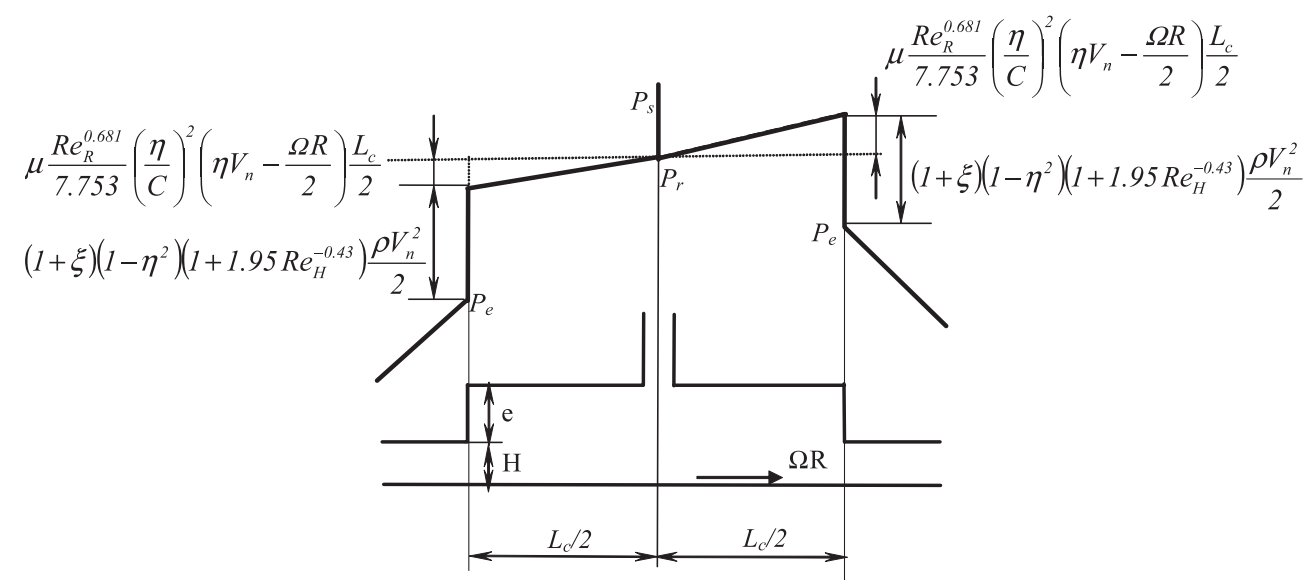

Fig. 5. Pressure patterns in the circumferential direction.

containing $R e_{H}$ is neglected. Distinction can also be made between the pressure drop coefficient $\xi$ in the axial and in the circumferential direction.

\subsubsection{Pattern 2: non-constant pressure [10]}

A refined pressure pattern was developed by San Andrés [10] and takes into account the influence of the hydrostatic and of the hydrodynamic effect generated in the circumferential direction in a shallow recess at high Reynolds number. This pattern is depicted in Figure 5.

$$
\begin{aligned}
& P_{\mathrm{e}}=P_{\mathrm{r}} \pm \Delta P_{\substack{\text { shallow } \\
\text { recess }}}-\Delta P_{\text {redge }} \\
& \Delta P_{\text {shallow }}=\mu \frac{R e_{\mathrm{R}}^{0.681}}{7.753}\left(\frac{\eta}{C}\right)^{2}\left(\eta V_{\mathrm{n}}-\frac{\Omega R}{2}\right) \frac{L_{\mathrm{c}}}{2} \\
& R e_{\mathrm{R}}=\frac{\rho|\Omega R|(C+e)}{\mu}
\end{aligned}
$$

According to Figure 5 that depicts a schematic description of the pressure surface shown in Figure 3b, the recess pressure, $P_{\mathrm{r}}$, is now the pressure level at the exit of the orifice. The second term on the right hand side of Equation (9), $\Delta P_{\text {shallow }}$, takes into account the combined contributions of the hydrostatic and of the hydrodynamic effect on the upstream and downstream edges of a shallow recess; pressures are linearly interpolated between the orifice exit section and the recess edge. The combined hydrostatic and hydrodynamic effects have a positive contribution toward the downstream edge and a negative one toward the upstream edge of the recess. The pressure drop at the recess edge $\Delta P$ recess is given by relation (8) and the pressure pattern is constant toward the axial direction of the recess.

The edge pressures determined either with relation (7) or with relation (9) are the boundary conditions for the thin film land equations. These boundary conditions are non-linear because they are coupled with the thin film edge normal velocity $V_{\mathrm{n}}$. In both cases they contain the recess pressure at the exit of the orifice, $P_{\mathrm{r}}$, which is part of the solution and acts as a parameter enabling the pressure pattern to adapt to local flow conditions. The film edge normal velocities and the edge film thickness describe these local flow conditions. A supplementary equation of mass flow rate balance in the recess has to be used for determining the recess pressure at the exit of the orifice.

$$
\frac{\partial \vartheta}{\partial t}=C_{D} \frac{\pi d_{\text {orifice }}^{2}}{4} \sqrt{\frac{2\left(P_{\mathrm{s}}-P_{\mathrm{r}}\right)}{\rho}}+\int_{\text {recess edge }} V_{\mathrm{n}} H \mathrm{~d} \gamma
$$

\section{Numerical solution}

The supply and the axial exit pressures are generally known parameters. The recess pressures at the exit of the orifices are obtained as the solution of the non-linear algebraic system obtained by writing the mass flow conservation Equation (11) for each pocket. The solution is obtained by using a Newton-Raphson algorithm that starts with an informed guess of $P_{\mathrm{r}}$ in each recess. Knowing the recess pressures at the orifice exit enables the estimation of the recess edge values $P_{\mathrm{e}}$ used as boundary conditions for the thin film equations. The bulk-flow system of equations is discretized by using rectangular finite volumes that cover the thin film land and a converged solution is obtained by employing the SIMPLE algorithm [1]. Once a converged solution is obtained, the edge normal velocities are available and the mass flow rate balance equations can be calculated for each recess. The recess pressures are then modified by the Newton-Raphson algorithm in order to ensure the conservation of the recess mass flow rate. The computational process might be time consuming because at each step of the Newton-Raphson algorithm one must calculate a Jacobean matrix with a rank equal to the number of recesses. The terms of the Jacobean matrix are calculated by giving small perturbations to the $P_{\mathrm{r}}$ variables. 


\section{Results}

A five recess HJB taken from [11] is used for illustrating the influence that the pressure pattern can have on the dynamic characteristics. The bearing has $76.2 \mathrm{~mm}$ in length, $76.2 \mathrm{~mm}$ in diameter with five equally spaced square recesses of $27 \mathrm{~mm}$ in length and $0.254 \mathrm{~mm}$ in depth. Each recess is fed via a centered orifice of $2.49 \mathrm{~mm}$ in diameter and with a discharge coefficient of 0.86 . This value of the discharge coefficient was taken from reference [11] where it was tuned for obtaining the best mass flow correlation between experimental and theoretical results. The bearing has a radial clearance of $0.127 \mathrm{~mm}$. Test data are available at three rotation speeds (10200, 17400 and $24600 \mathrm{rpm})$ and three supply pressures $(4,5.5$ and $7 \mathrm{MPa}$ ). The fluid was water at $55^{\circ} \mathrm{C}$. A zero pressure drop coefficient $\xi$ was considered in Equations (7) and (9) and walls were considered as hydraulically smooth. Measured dynamic coefficients taken from [11] are compared with theoretical predictions obtained by using both pressure patterns.

From the theoretical standpoint, the dynamic regime is described as a small amplitude motion of the rotor about an equilibrium position. Following the traditional small perturbation approach, all variables are decomposed as $\Phi=\Phi_{0}+\varepsilon \Phi_{1}$ where $\varepsilon \ll 1$ is the perturbation parameter. The introduction of this decomposition in the unsteady bulk-flow equations gives two systems of equations. The zeroth order part is the original system excepting the unsteady terms. The perturbed (first order) system consists of linearized equations and has exactly the same form as the original system of bulk-flow equations. The problem was extensively described in the lubrication related literature $[2,12]$ and will not be further detailed. The system of first order bulk-flow equations is solved using the same SIMPLE and Newton-Raphson algorithms. Forces arising from perturbations are obtained by integrating the first order pressure field and are expressed via the dynamic coefficients. For displacement perturbations these forces are defined as:

$$
\begin{gathered}
-\left\{\begin{array}{c}
F_{X 1} \\
F_{Y 1}
\end{array}\right\}=\left[\begin{array}{ll}
K_{X X} & K_{X Y} \\
K_{Y X} & K_{Y Y}
\end{array}\right]\left\{\begin{array}{c}
e_{X 1} \\
e_{Y 1}
\end{array}\right\} \\
+\left[\begin{array}{ll}
C_{X X} & C_{X Y} \\
C_{Y X} & C_{Y Y}
\end{array}\right]\left\{\begin{array}{l}
\dot{e}_{X 1} \\
\dot{e}_{Y 1}
\end{array}\right\}+\left[\begin{array}{ll}
M_{X X} & M_{X Y} \\
M_{Y X} & M_{Y Y}
\end{array}\right]\left\{\begin{array}{l}
\ddot{e}_{X 1} \\
\ddot{e}_{Y 1}
\end{array}\right\}
\end{gathered}
$$

Only centered (zero eccentricity) results are considered in the present work and are presented in Figures 6-9. Figure 6 depicts the direct stiffness coefficient, $K_{X X}=$ $K_{Y Y}$. The theoretical predictions and the measured coefficients are in good agreement. It can be seen that there is little difference between the results obtained with the constant and with the variable pressure patterns. The cross coupling stiffness coefficient, $K_{X Y}=-K_{Y X}$, is depicted in Figure 7 . The theoretical coefficients have the same trends as the measured ones but the values are

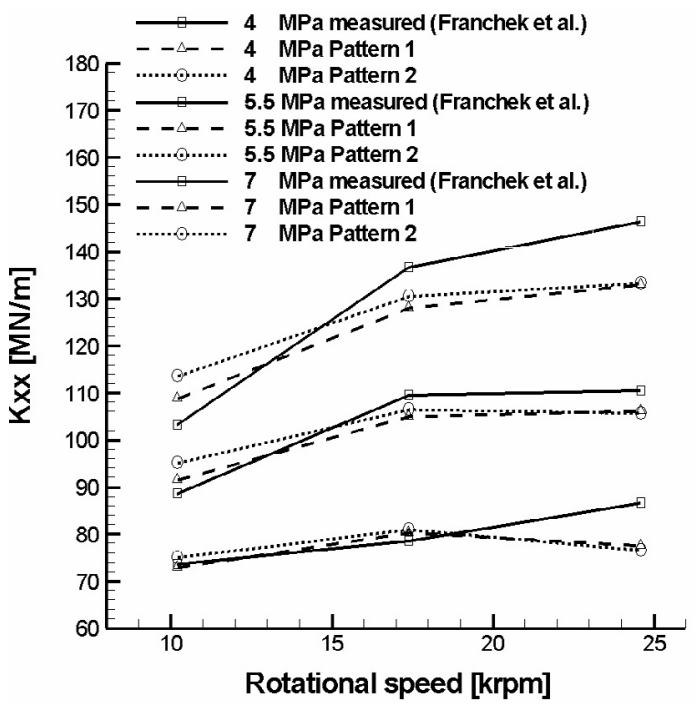

Fig. 6. Direct stiffness.

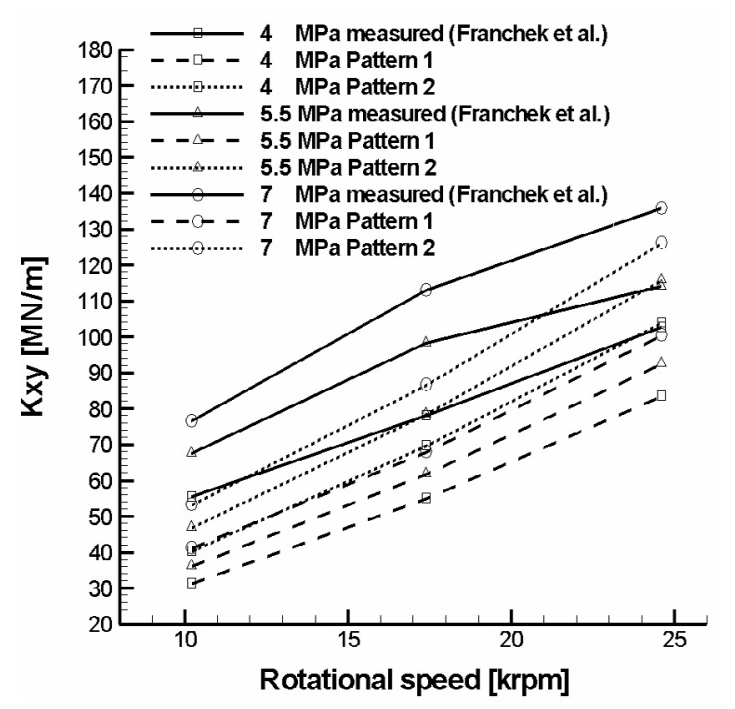

Fig. 7. Cross coupling stiffness.

underpredicted. Nevertheless, the results obtained with the non-constant pressure pattern show a clear improvement over those obtained with the constant pressure pattern. This is the most important result arising from the use of the non-constant pressure pattern. Figure 8 depicts the direct damping coefficient, $C_{X X}=C_{Y Y}$. The constant and the non-constant pressure patterns give the same results that are lower than experimental data. Finally, the dynamic behavior of the bearing is characterized by the whirl frequency ratio parameter, $W F R=$ $\omega / \Omega=K_{X Y} / C_{X X} \Omega$. The whirl frequency usually corresponds to the first critical speed of a rigid rotor supported on fluid film bearings and is usually presented as a fraction of the rotor speed. Comparisons of the numerical predictions with values obtained from measured coefficients are depicted in Figure 9 and show a clear improvement of the theoretical predictions when using the non-constant pressure pattern. 


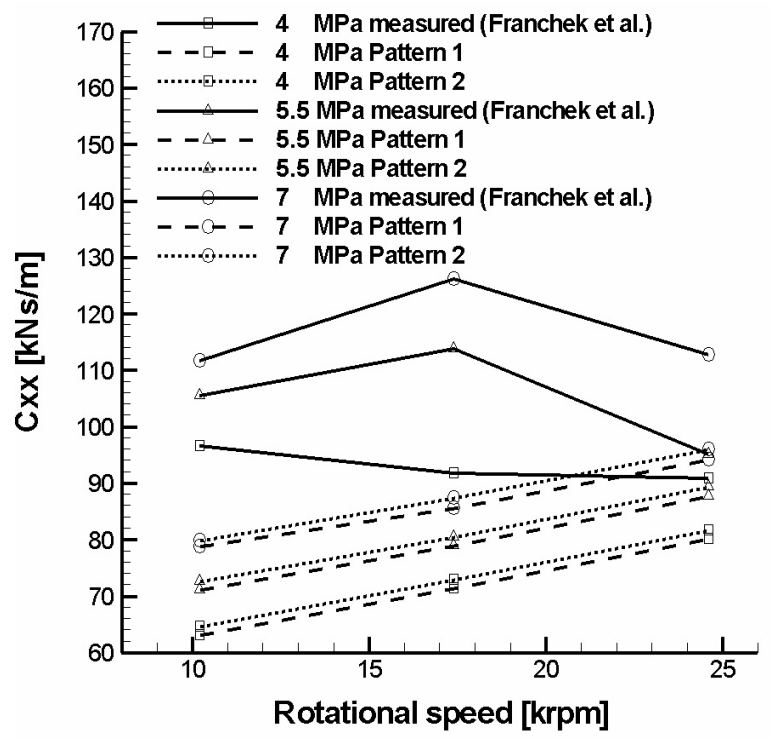

Fig. 8. Direct damping.

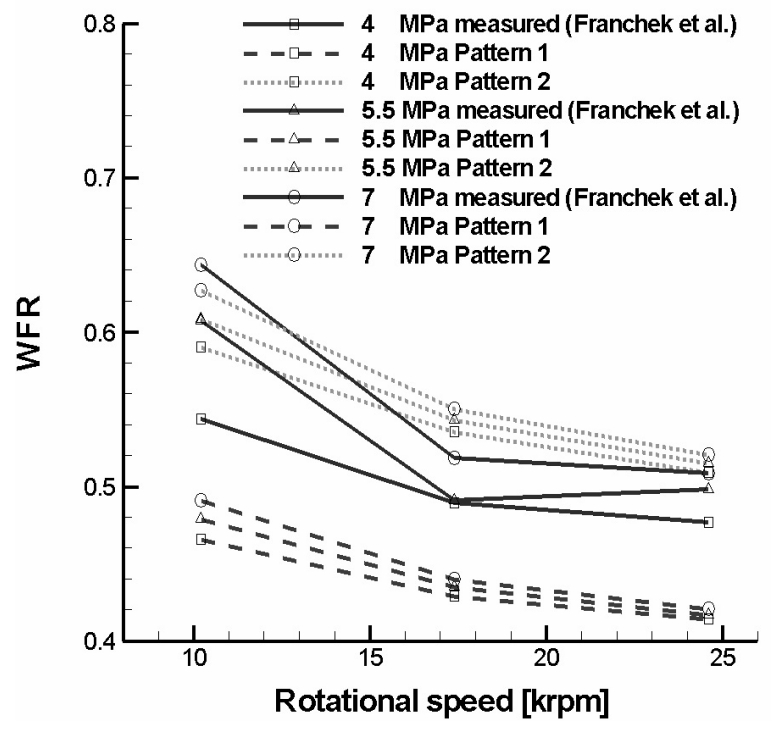

Fig. 9. Whirl frequency ratio.

\section{Summary and conclusions}

The goal of the present work was to underline the importance of the pressure pattern used for modelling the dynamic characteristics of hybrid journal bearings working at important supply pressures and with high rotational speeds. The usual practice for deep-pocket hydrostatic journal bearings is to consider a constant recess pressure level. This approach might be insufficient for correctly modelling hybrid journal bearings especially for shallow recesses. Complete Navier-Stokes calculation shows that in this case the circumferential pressure pattern is influenced by hydrostatic and by hydrodynamic effects. A constant and a non-constant pressure pattern, both taken from [10], have been used for comparing theoretical predictions of rotordynamic coefficients with measured results. It has been shown that both pressure patterns give similar results for the direct stiffness and for the direct damping but the second non-constant pattern leads to a net improvement in the prediction of the cross coupling stiffness. The whirl frequency ratio is thus much better predicted with the second pressure pattern. The main conclusion is then that the non-constant pressure pattern should always be used instead of the constant one especially for severe working conditions and shallow recesses.

\section{References}

[1] B.E. Launder, M. Leschziner, Flow in Finite-Width, Thrust Bearings Including Inertial Effects, ASME J. Lubrication Technology (1978) 330-338

[2] D.W. Childs, Turbomachinery Rotordynamics: Phenomena, Modeling and Analysis, Wiley Interscience, New York, 1993

[3] J.P. Chaomleffel, D. Nicolas, Experimental Investigations of Hybrid J. Bearings, Trib. Int. (1985) 253-259

[4] L. San Andres, J. Velthuis, Laminar Flow in a Recess of a Hydrostatic Bearing, STLE Paper No. 91TC3Bd3, STLE/ASME Tribology Conference, October 1991, St. Louis, Missouri

[5] M.J. Braun, M. Dzodzo, Effects of the Feedline and Hydrostatic Pocket Depth on the Flow Pattern and Pressure Distribution, paper No. 94-Trib-27, ASME/STLE Tribology Conference, Maui, Hawaï, October 16-19, 1994

[6] M.J. Braun, M. Dzodzo, S. Lattime, Some qualitative and quantitative aspects of flow in a hydrostatic journal bearing pocket, FED-Vol. 239, Fluid Engineering Division Conference Vol. 4 ASME, 1996, pp. 109-114

[7] M.J. Braun, M. Dzodzo, A Three Dimensional Model for a Hydrostatic Bearing, 32nd AIAA/ASME/SAE/ASEE Joint Propulsion Conference July 1-3, 1996/Lake Buena Vista, FL

[8] M.J. Braun, M. Dzodzo, Three dimentional flow and pressure patterns in a hydrostatic journal bearing pocket, ASME J. Trib. (1996) 711-719

[9] G.G. Hirs, A bulk flow theory for turbulence in lubricant films, ASME J. Lubrication Technology (1973) 146-173

[10] L. San Andrés, Turbulent Hybrid Bearings With Fluid Inertia Effects, ASME J. Trib. (1990) 699-207

[11] N.M. Francheck, D.W. Childs, L. San Andrés, Theoretical and experimental comparisons for rotordynamic coefficients of high-speed, high-pressure, orifice-compensated hybrid bearing, ASME J. Trib. (1995) 285-290

[12] J. Frêne, D. Nicolas, B. Degueurce, D. Berthe, M. Godet, Lubrification hydrodynamique. Paliers et butées, Collection de la Direction des Études et Recherches d'Électricité de France, Éditions Eyrolles, 1990 